\title{
A VACINAÇÃO INFANTIL E AS REAÇÕES EMOCIONAIS DAS MÃES: análise e contribuições do design para experiência
}

\author{
CHILDHOOD IMMUNIZATION AND THE EMOTIONAL REACTIONS OF \\ MOTHERS DURING THE VACCINATION PROCESS: \\ analysis and contribution of the design for experience \\ SCHERDIEN, Ingrid; Mestre. \\ Universidade do Vale do Rio dos Sinos - UNISINOS \\ ingridesigner@gmail.com \\ RODRIGUES, Priscila; Mestre. \\ Universidade do Vale do Rio dos Sinos - UNISINOS \\ prickapricka@yahoo.com.br \\ MELLO, Daniele de; Mestre. \\ Universidade do Vale do Rio dos Sinos - UNISINOS \\ danidemello@gmail.com
}

\begin{abstract}
Resumo: Este artigo apresenta uma pesquisa de caráter exploratório, que buscou identificar as reações emocionais de mães no processo de vacinação de seus filhos, bem como as causas dessas reações e as expectativas quanto ao uso dos produtos e serviços envolvidos no processo de vacinação infantil. Para elaborar tal estudo, apoiou-se no design para experiência e na teoria dos appraisals para aplicação do modelo de avaliação temática em entrevistas em profundidade. Para fundamentar a teoria sobre design para experiência, emoções e teoria dos appraisals, utiliza-se Demir, Desmet e Hekkert (2009), Scherer, Schorr e Johnstone (2001) e Tonetto e Costa (2011) como os principais autores. O intuito da pesquisa consistiu em apontar diretrizes projetuais que possam minimizar ou potencializar as emoções identificadas nas mães.
\end{abstract}

Palavras-chave: vacinação infantil, reações emocionais, design para experiência, teoria dos appraisals, diretrizes projetuais.

Abstract: This paper presents an exploratory study that sought to identify possible emotional reactions of mothers during the vaccination process of their children, as well, the causes of these emotions and the concerns related to the use of products and services involved in child immunization process. In this way, the study relies in the context of design for experience and the appraisals theory for applying thematic evaluation model on interviews. To support the theory of design for experience, emotions and 
theory of appraisals, we use Demir, Desmet and Hekkert (2009), Scherer, Schorr and Johnstone (2001) and Tonetto and Costa (2011) as the main authors. The aim of the research is to indicate project design guidelines that can minimize or maximize the emotions identified in mothers.

Keywords: childhood immunization, emotional reactions, design for experience, appraisal theory, design project guidelines.

\section{INTRODUÇÃO}

A vacinação infantil é o primeiro passo para a prevenção de doenças virais. De acordo com Varella (2012), as vacinas proporcionam à criança proteção ao sistema imunológico e maiores chances de um desenvolvimento com saúde. Ainda auxiliam na erradicação de determinadas doenças nos países em que ocorrem as campanhas de vacinação. Embora a vacinação seja uma ação para o bem-estar individual e coletivo, percebe-se que, no Brasil, a grande concentração de doses durante os primeiros seis meses de idade das crianças proporciona alguns desconfortos físicos e emocionais, tanto para a criança, quanto para seus pais e responsáveis.

Por essa razão, procurou-se investigar, quanto ao processo de vacinação infantil, quais as reações emocionais das mães, as causas dessas reações, bem como os concerns - que compreende as expectativas, os objetivos, as necessidades e as percepções das mães quanto ao uso dos produtos e serviços disponibilizados para a vacinação. Para desenvolver tal estudo, utilizou-se a teoria dos aprraisals, especificamente o modelo temático de avaliação das emoções, para embasar a construção, aplicação e análise da pesquisa. $O$ estudo insere-se no contexto do design para experiência, a fim de apontar, por meio de diretrizes projetuais, soluções que potencializem ou minimizem as reações emocionais das mães.

Assim, este artigo é resultado de uma pesquisa exploratória, utilizando como método entrevistas em profundidade com oito mães de crianças entre zero e quatro anos de idade, em período de intensa vacinação. Além disso, para fundamentar a teoria sobre design para experiência, emoções e teoria dos appraisals, utiliza-se Demir, Desmet e Hekkert (2009), Scherer, Schorr e Johnstone (2001) e Tonetto e Costa (2011) como os principais autores.

\section{EMOÇÃO E DESIGN PARA EXPERIÊNCIA - CONSIDERAÇÕES TEÓRICAS}

As experiências pessoais, segundo Holbrook e Hirschman (1982), são decorrentes de eventos carregados de significados emocionais e frutos da interação entre os usuários e um conjunto de estímulos, sejam esses estímulos os produtos, serviços ou comunicação. De acordo com Scherer (2005), entende-se que um acontecimento, ao qual um organismo se expõe, estimula, após ser avaliado e significado, uma resposta específica. Relacionando o design a esse conceito, projeta-se não só a forma e a função dos artefatos, mas busca-se, além disso, compreender os produtos e serviços considerando as experiências e as emoções dos indivíduos.

Atuando em um nível estratégico, o design busca novos aportes para o processo de projeto em outras áreas de estudos. Segundo Tonetto e Costa (2011), no que abarca a psicologia, possibilitou-se o reconhecimento de que determinadas emoções, quando pretendidas, podem ser obtidas ou minimizadas por meio de 
projetos. Para os autores, o design para experiência, na medida em que representa um grande avanço no sentido de atender de modo inovador e competitivo as necessidades e desejos dos indivíduos, amplia a visão do designer e apresenta relação íntima com questões estratégicas.

Dessa forma, pode-se refletir sobre o motivo pelo qual as emoções tornam-se relevantes para os projetos de design. Segundo Lazarus (1991), emoções expressam significados individuais em um determinado contexto. As pessoas são influenciadas pelas emoções, as quais contribuem para a própria saúde física e mental dos indivíduos. Para o autor, não há como dissociar cognição, motivação, adaptação e atividade fisiológica. A partir de uma reação emocional pode-se aprender sobre a sua interação e relacionamento com o meio. Nesse mesmo contexto, Desmet e Hekkert (2007) citam que a emoção, que é resultado de um processo cognitivo, é causada pela interpretação de um evento ou produto.

Nessa relação de interação e interpretação entre humano e produto-serviço, consideram-se, de acordo com Desmet e Hekkert (2007), três dimensões da experiência. Para os autores, essas dimensões compreendem: a experiência de significado (atribuição de significado através dos processos cognitivos); a experiência estética (o prazer estético através dos sentidos, sensações e percepções); e a experiência emocional (a resposta emocional demonstrada pelas emoções e sentimentos). Desmet (2002), nesse contexto, afirma que as emoções são mais relevantes para a experiência, pois possibilitam a identificação de reações afetivas nas interações dos indivíduos com os produtos e serviços, preenchendo lacunas de informação e influenciando mais fortemente a tomada de decisões.

De acordo com essa perspectiva, Meroni e Sangiorgi (2011) citam que o design para experiência implica em compreender os aspectos emocionais da interação das pessoas com objetos, ambientes e demais indivíduos. Já para Demir, Desmet e Hekkert (2009), o projeto de design objetiva potencializar ou minimizar determinadas emoções. Sendo assim, faz-se importante identificar as causas das reações emocionais dos usuários, de acordo com as suas necessidades e expectativas.

É fundamental destacar que não é possível entender a emoção fora do contexto em que ela ocorre. Por isso, Tonetto e Costa (2011) afirmam que o profissional de design, com o objetivo de projetar para experiência, não deve limitar-se às suas próprias crenças e vivências, pois estas podem apresentar-se muito diferentes das crenças e vivências dos usuários aos quais se destina o projeto. Verifica-se, por esse motivo, a importância de uma análise que possa explicitar as emoções e auxiliar a identificação das causas que as despertaram, sejam essas emoções positivas ou negativas. A fim de melhor compreender como se dá esse processo, o design pode apropriar-se da teoria dos appraisals.

Um appraisal, segundo Lazarus (1991), é uma avaliação das relações com o meio ambiente feitas pelo próprio indivíduo. Scherer, Schorr e Johnstone (2001) esclarecem que, em uma forma simplificada, a teoria dos appraisals é o modo como emoções são eliciadas por avaliações de eventos e situações. Demir, Desmet e Hekkert (2009) complementam que essa teoria busca resultados das avaliações como um diagnóstico sobre as relações de bem-estar do indivíduo e os efeitos proporcionados pelo entendimento ou exploração da interação do homem com o produto. Portanto, de acordo com a teoria dos appraisals, a emoção é provocada por uma avaliação 
(appraisal) de um determinado evento ou situação, que pode ser considerada, ou não, potencialmente benéfica (DESMET; HEKKERT, 2007).

No contexto da teoria dos appraisals, as preocupações, expectativas, objetivos e interesses dos usuários quanto ao uso do produto ou serviço compreendem os concerns, que auxiliam no entendimento das expectativas dos usuários que acabam por processar suas avaliações. No modelo de Desmet (2002) - que é baseado na teoria dos appraisals e busca propor uma forma de compreender a relação emocional das pessoas com produtos (TONETTO; COSTA, 2011) -, as emoções envolvem três aspectos principais: avaliação, preocupação e estímulo. Para Desmet (2002), as interações entre estes aspectos evocam as emoções. Compreende-se que, neste aprofundamento, o designer pode realizar suas interferências projetuais.

A literatura reporta ainda duas abordagens proeminentes na descrição e diferenciação entre appraisals: avaliação componencial e avaliação temática. A abordagem componencial é descrita por meio de várias questões. Cada questão tem como foco um aspecto diferente da situação. As respostas dadas para cada questão são nomeadas como os componentes dos appraisals, e cada emoção distinta envolve um padrão particular desses componentes (DEMIR; DESMET; HEKKERT, 2009). Por outro lado, segundo os autores citados, na abordagem temática descrevem-se os appraisals de modo mais abstrato, a partir de declarações que refletem o significado pessoal de uma situação - o que constitui os temas dos appraisals. Cada emoção descrita envolve um significado pessoal distinto. Complementa-se, com apoio de Scherer, Schorr e Johnstone (2001), que este tipo de modelo proporciona a compreensão da origem de uma emoção, como ela é combinada, integrada e assimilada a um padrão.

Para Demir, Desmet e Hekkert (2009), ambas as abordagens de avaliação podem ser úteis no entendimento e projetação para emoções. A avaliação componencial, por exemplo, é mais utilizada em pesquisas para projetos de produtos, porque contribui de maneira específica para a caracterização de determinados pontos como o tipo de material a ser utilizado. Entretanto, a avaliação temática é alternativa viável, que pode contribuir também para a concepção de projetos de serviços. Verificase, dessa forma, que a abordagem temática fornece mais do que a soma dos componentes, porque pode proporcionar uma compreensão integral das emoções intencionadas. Nessa avaliação, com um processo de questionamentos mais amplo, vai-se até o âmago do assunto que está sendo pesquisado, possibilitando que o problema seja identificado sem deixar questões superficiais mascararem o que realmente necessita ser resolvido.

Conclui-se, portanto, que projetar para experiências emocionais torna-se um fator relevante para a atividade de design. Relacionando o contexto teórico ao tema deste artigo, podem ser traçadas diretrizes projetuais de produtos e serviços com o intuito de potencializar reações positivas e minimizar reações negativas na interação entre as mães e o processo de vacinação de seus filhos.

\section{A VACINAÇÃO INFANTIL E AS REAÇÕES EMOCIONAIS}

Segundo o Portal da Saúde (2012), uma das principais maneiras de prevenir doenças em crianças é por meio da vacinação. No Brasil, as vacinas são disponibilizadas gratuitamente em postos de saúde públicos ou com a contratação de serviços em clínicas particulares. Esse serviço apresenta-se em rápida evolução e 
posiciona o país entre os mais avançados no desenvolvimento de vacinas. O resultado deste investimento reflete em vacinas mais completas em doses únicas.

Além disso, o Portal da Saúde (2012) informa que para a organização do sistema de vacinação foi criado o Programa Nacional de Imunizações (PNI) pela Secretaria de Vigilância em Saúde do Ministério da Saúde, no ano de 1973. O objetivo deste programa consiste em facilitar o acesso às vacinas através de campanhas e ações pontuais a fim de eliminar e controlar doenças no país, proporcionando assim, melhores condições de saúde para a população brasileira. O programa presta serviços gratuitamente, tais como: registro e aplicação de doses da vacina, logística dos materiais necessários, eventos para a promoção da vacinação, acompanhamento de reações adversas, supervisão dos resultados por estado e por sala de vacinação e sistema de informações imunológicas. Para alcançar a eficiência pretendida, o PNI promove a vacinação infantil das crianças que, por sua vez, recebem em torno de 32 tipos diferentes de vacinas. O Portal Brasil (2012) apresenta uma tabela de orientações para aplicação de cada vacina de acordo com a faixa etária da criança. Essa tabela é fornecida aos pais na aplicação da primeira vacina, mantendo todos os registros sobre o desenvolvimento físico e biológico da criança.

Pode-se observar que, de modo geral, em relação ao calendário de vacinação, crianças de zero a quatro anos passam por um período de intensa vacinação, realizadas por injeções ou gotinhas. Ao experimentar a vacina, as crianças choram e se esquivam, ou seja, manifestam reações que, embora sejam desagradáveis, são aparentemente naturais em virtude da ação dolorosa realizada. No entanto, os pais e as mães das crianças, que as acompanham na vacinação, também manifestam emoções pelo fato de ver seu filho passando por um processo doloroso.

A questão da vacinação infantil preocupou as autoras deste artigo, pois se trata de uma rotina obrigatória a todos aqueles que têm filhos, principalmente às mães, que acabam por acompanhar o processo de vacinação de modo mais frequente do que os pais, geralmente. Com o foco da pesquisa concentrado nas mães e não nas crianças, surgiu o interesse em investigar as reações emocionais das mães em relação ao processo de vacinação de seus filhos, identificando quais emoções seriam essas e as suas devidas causas. Para responder a esses questionamentos, foi seguido um método de pesquisa, explicitado a seguir.

\section{MÉTODO DE PESQUISA E COLETA DAS INFORMAÇÕES}

Utilizando-se de pesquisa exploratória, foram realizadas entrevistas em profundidade considerando o critério de saturação, ou seja, a pesquisa foi encerrada quando as respostas encontradas nas últimas entrevistas não apresentaram novas informações em relação às entrevistas anteriores. Sendo assim, foram entrevistadas oito mães ao todo, com filhos na idade entre zero e quatro anos, que vacinam seus filhos tanto em clínicas particulares, quanto em postos de saúde públicos da região de Porto Alegre, no Rio Grande do Sul, Brasil. Entendeu-se que, entrevistando ambos os perfis, seriam obtidos maiores insumos para discussão.

A coleta das informações foi realizada mediante entrevistas em profundidade, semiestruturadas, com base na teoria dos appraisals segundo o modelo temático de avaliação, que proporciona respostas mais abstratas, mas ao mesmo tempo uma compreensão integral das emoções intencionadas. O objetivo consistia em identificar 
as reações emocionais das mães, as causas destas emoções e os concerns relacionados ao uso dos produtos e serviços durante o processo de vacinação.

As entrevistas foram realizadas nas casas das mães, no ambiente em que se sentiam mais confortáveis para a conversa, que foi gravada em áudio. O roteiro da entrevista não apresentava perguntas totalmente formatadas, justamente por ser semiestruturado, mas sim orientações sobre o que questionar: qual a idade do filho; como era a saúde e a personalidade da criança; onde e como era o local da vacinação; quais os problemas e vantagens do local de vacinação; como eram e como procediam os profissionais de saúde do local; como a criança reagia nos diversos procedimentos de vacinação; e, por fim, como a mãe se sentia em relação a determinadas situações pontuadas. O roteiro ia sofrendo ajustes e variando sua ordem de acordo com o modo como as mães eram estimuladas por suas respostas.

\section{ANÁLISE E DISCUSSÃO DAS INFORMAÇÕES}

Para fins de análise de conteúdo, as entrevistas foram transcritas e as manifestações verbais das mães foram organizadas em um quadro, relacionando as falas que justificaram o foco do assunto. Desse modo, foi possível apontar as emoções manifestadas nas descrições realizadas pelas mães, os concerns, bem como as causas dessas emoções.

A análise realizada requereu interpretação subjetiva das autoras deste artigo, que observaram as falas propriamente ditas, a entonação da voz das mães entrevistadas e as expressões demonstradas no momento da entrevista. Algumas mães também foram específicas quanto a seus sentimentos. Por exemplo, em determinada fala, a mãe utiliza-se da palavra 'tensão' para descrever seu sentimento quando houve mudanças em determinada vacina. Considerando-se também a entonação da voz da mãe, suas expressões aparentes no momento da entrevista e o contexto do que ela estava explanando, as pesquisadoras consideraram que o sentimento exposto era de apreensão, relacionado ao nervosismo e ao medo por desconhecer a nova vacina e as reações que ela poderia causar.

Assim, de modo a obter uma consistência nas relações propostas, as emoções identificadas na pesquisa realizada com as mães foram categorizadas com base na classificação das emoções elaboradas por Parrott (2011). A classificação proposta por esse autor prevê a categorização das emoções em primárias, secundárias e terciárias, sendo que as emoções primárias estão organizadas em seis categorias: amor, alegria, surpresa, raiva, tristeza e medo, e estas se desdobram em emoções secundárias e terciárias. A partir da análise do conteúdo das entrevistas realizadas com as mães foram identificadas cinco emoções terciárias: apreensão, insegurança, irritação, angústia e segurança. Com as emoções terciárias, foi possível verificar de quais emoções primárias e secundárias são provenientes, como mostra o Quadro 1, ampliando a visão sobre as causas emocionais nas interações das mães com o sistema de vacinação. 
Quadro 1 - Emoções terciárias identificadas nas entrevistas.

\begin{tabular}{|l|l|l|}
\hline \multicolumn{3}{|l}{ Classificação das emoções (PARROT, 2001) } \\
\hline Primárias & Secundárias & Terciárias \\
\hline Medo & Nervosismo & Apreensão \\
\hline \multirow{2}{*}{ Tristeza } & Negligência & Insegurança \\
\cline { 2 - 3 } & Sofrimento & Angústia \\
\hline Raiva & Irritação & Irritação \\
\hline Alegria & Contentamento & Segurança \\
\hline
\end{tabular}

Fonte: Elaborado pelos autores, com base na pesquisa realizada.

Considerando as emoções terciárias identificadas na análise das entrevistas, apresenta-se abaixo o Quadro 2, uma síntese que exemplifica uma das falas das mães para cada emoção encontrada nas análises. Em seguida, são aprofundadas as análises e discutidas cada uma das emoções identificadas.

Quadro 2 - Exemplos de concerns, emoções e causas identificadas nas entrevistas.

\begin{tabular}{|c|c|c|c|}
\hline Concern & Emoção & Causa & Exemplo de evidências na fala \\
\hline $\begin{array}{l}\text { Receber claras } \\
\text { informações sobre as } \\
\text { vacinas e } \\
\text { procedimentos. }\end{array}$ & Apreensão & $\begin{array}{l}\text { Falta de clareza } \\
\text { nas informações. }\end{array}$ & $\begin{array}{l}\text { "Quando mudou a vacina da paralisia, de gotinha } \\
\text { para injeção, a enfermeira ficou fazendo muitas } \\
\text { perguntas para o médico, ai eu comecei a ficar } \\
\text { tensa, será que vão aplicar uma vacina errada? Ai } \\
\text { eu fiquei de olho. Mas ela só estava tirando } \\
\text { dúvidas. Mas eu sempre fico de olho." }\end{array}$ \\
\hline $\begin{array}{l}\text { Ter um ambiente } \\
\text { higienizado. }\end{array}$ & Insegurança & Falta de higiene. & $\begin{array}{l}\text { "Até no próprio lugar, um local melhor pra colocar } \\
\text { teu filho, higienizado, porque a gente sente que } \\
\text { não tem nenhuma higienização do próprio } \\
\text { ambiente, onde coloca a criança deitada, entra } \\
\text { uma e sai outra." }\end{array}$ \\
\hline $\begin{array}{l}\text { Ter uma } \\
\text { infraestrutura } \\
\text { adequada. }\end{array}$ & Irritação & $\begin{array}{l}\text { Problemas na } \\
\text { infraestrutura. }\end{array}$ & $\begin{array}{l}\text { "Fica todo mundo junto na recepção, mães, filhos, } \\
\text { idosos, qualquer pessoa que precisa ser vacinada. } \\
\text { Como a sala é maior, tu nem terminou a vacina, já } \\
\text { tem outra criança vindo, ou outro adulto no } \\
\text { mesmo espaço." }\end{array}$ \\
\hline $\begin{array}{l}\text { Ver o filho sentindo } \\
\text { dor. }\end{array}$ & Angústia & $\begin{array}{l}\text { Picada da agulha, } \\
\text { injeção } \\
\text { propriamente dita. }\end{array}$ & $\begin{array}{l}\text { "É difícil ver ela ter dor, eu preferiria que fosse em } \\
\text { mim, mas ao mesmo tempo eu sei que é } \\
\text { importante. É um aperto no coração, porque eu } \\
\text { fico pensando como é que ia ser se fosse em mim." }\end{array}$ \\
\hline $\begin{array}{l}\text { Ter um guia de } \\
\text { informações. }\end{array}$ & Segurança & $\begin{array}{l}\text { Recebimento da } \\
\text { caderneta de } \\
\text { saúde da criança. }\end{array}$ & $\begin{array}{l}\text { "Esse caderno é bem legal porque ele tem cada } \\
\text { vacina. Tem orientações." }\end{array}$ \\
\hline
\end{tabular}

Fonte: Elaborado pelos autores, com base na pesquisa realizada.

De acordo com a tabela de exemplo, verifica-se, a partir das análises realizadas, que o primeiro concern identificado compreende a expectativa das mães em receber informações claras sobre as vacinas que seriam aplicadas e sobre os procedimentos de vacinação. Mas o que as mães entrevistadas relataram encontrar nos postos de atendimento foi a falta de informações transmitidas pelos médicos e enfermeiras responsáveis pela aplicação das vacinas. Não explicitam qual vacina está sendo aplicada, nem registram as informações de modo objetivo na caderneta de vacinação, conforme se identifica na fala de uma das mães: - "Só tiram da geladeira a vacina e já aplicam. Podem estar aplicando qualquer coisa. E depois só escrevem qualquer coisa na caderneta. Se der algum problema, vou cobrar de quem? Não passa uma confiabilidade.". Além disso, segundo as mães entrevistadas, se elas não questionam insistentemente, os profissionais também não informam sobre as reações que a criança pode ter após a vacina, como febre, por exemplo, nem qual o procedimento 
que deveria ser adotado para a próxima dose, como evitar dar o leite materno alguns minutos antes da vacina. Quanto a isso, muitas mães entrevistadas também relataram receber informações contraditórias, dependendo do local de atendimento, com maiores problemas de comunicação nos postos de saúde públicos. A falta de informações provocou apreensão sobre os procedimentos por não atender as expectativas esperadas pelas mães. A desinformação pode causar apreensão a ponto de algumas mães se recusarem a vacinar seus filhos, pois têm medo do que pode ocorrer com a saúde das crianças: - "Se o médico não orientar não se sabe, porque tenho conhecidos que não sabem por que estão fazendo aquela vacina, ai nem fazem.".

Próximo da apreensão está a insegurança, principalmente em relação à falta de higienização do local de atendimento. Aqui a preocupação se manifesta tanto nos postos de saúde públicos, quanto nas clínicas privadas, pois as mães não têm a possibilidade de verificar os procedimentos de limpeza anteriores ao momento da vacinação, nem verificar se há negligência. A falta de higienização pode-se relacionar ao perigo de contaminação das crianças em contato com os utensílios utilizados, como o local onde a criança é colocada, materiais curativos e até a própria seringa: - "Fico com receio porque eles colocam um algodãozinho no lugar da vacina.". As mães entrevistadas gostariam de encontrar um ambiente bem cuidado, que estivesse atento aos procedimentos de esterilização do espaço destinado à vacinação. Esperam, como concern, que o local esteja limpo, mas não conseguem se sentir completamente seguras devido à rapidez e frequência que as crianças são atendidas. Neste aspecto, destaca-se o seguinte trecho explanado por uma das mães: - "Fico muito preocupada em relação à higiene. Eu levo um paninho e coloco o pano por cima da maca. Eu fico preocupada de ter algum sangue, alguma coisa que possa pegar nela e dar alergia.".

Além dos problemas quanto à higiene, no decorrer das entrevistas as mães manifestaram outra preocupação. Elas esperavam encontrar um local com infraestrutura adequada para a passagem de carrinhos de bebê, uma recepção tranquila para as crianças e um espaço reservado para a vacinação. Estes aspectos não contemplados ocasionaram irritação nessas mães. Muitas das mães entrevistadas manifestaram o interesse em encontrar um local bem preparado, que apresentasse, inclusive, aspectos lúdicos: - "Tem que ter uma coisa para atrair ele, para ter um entretenimento e diminuir o trauma, porque tem adulto que tem medo, quem dirá eles. Tu chega ali, tu já entra, elas vão fazer a vacina e deu, não tem brinquedinho para eles.". Outra mãe também afirmou: - "Podia ter uma sala de coleta infantil, ter algo mais alegre, divertido para as crianças.". No que abrange a acessibilidade nos locais de vacinação, destaca-se: - "O espaço não é muito pensado para as mães, o carinho de bebê, por exemplo, não passa no corredor, ai para levar ela, eu preciso tirá-la do carinho.". Quanto ao espaço para vacinação, muitas das mães entrevistadas fizeram criticas, como se destaca nas falas: - "Tem que ter uma sala só de vacinação, pois geralmente é junto com os outros atendimentos.", afirma uma mãe. Já outra, reforça o fato desagradável de ficarem todos juntos na mesma recepção, geralmente lotadas e desorganizadas, inclusive nas clínicas particulares, que agrupam mães, crianças, idosos, pessoas já doentes, qualquer um que precise ser vacinado.

Além das reações emocionais já abordadas, a angústia também é manifestada em virtude da sensação de dor que é causada ao filho no momento da vacinação. Embora as mães entrevistadas saibam que as vacinas trazem benefícios para as crianças e que a dor é um aspecto físico praticamente inevitável, é angustiante 
presenciar a dor do filho, conforme as mães. Identificam-se, nesse sentido, algumas declarações: - "Quando ela era menor, ai eu ficava muito angustiada, ficava mesmo. Quando ela era bebê, com certeza doía mais em mim do que nela."; - "Na hora de segurar a mãozinha dela na hora da vacina eu fecho os olhos pra não chorar."; - "Eu odeio ver ela ter dor, eu preferiria que fosse em mim, com certeza, mas ao mesmo tempo eu sei que é importante".

Observou-se, portanto, que as reações emocionais negativas são predominantes, mas também foi possível encontrar um ponto positivo que gerou segurança nas mães: o concern relativo à expectativa de um guia de informações. Embora apreensivas quanto à confusão e à falta de informações dos médicos e enfermeiras, muitas mães encontraram na caderneta de saúde da criança, a segurança que precisavam: - "Tanto postos públicos quanto clínicas privadas dão a caderneta. Azul para os meninos, rosa para as meninas. Ela tem todas as informações sobre a saúde da criança.". As mães entrevistadas apontaram a caderneta como algo útil por indicar todas as vacinas que devem ser realizadas, além de conter registros e informações sobre a saúde infantil, relativos ao desenvolvimento físico e mental das crianças. Além do mais, algumas mães destacaram positivamente o aspecto visual da caderneta.

Com as análises, foi possível perceber que a relação de bem-estar entre mãe e filho é forte, principalmente nos primeiros meses de vida, nos quais a criança é alimentada por meio da amamentação. Nesse sentido, garantir o bem-estar emocional das mães torna-se relevante, mesmo que a sensação física de dor, pela injeção, não seja nelas. Uma das mães entrevistadas, afirmou: - "Se eu fico bem, dou mamá melhor e ele também fica mais tranquilo.". Compreende-se com essa pesquisa que as reações emocionais das mães podem interferir nas reações das crianças.

Com isso, amenizar a apreensão, a insegurança, a irritação, a angústia e potencializar a segurança no momento da vacinação, se faz de suma importância. $O$ design para experiência pode valer-se dos resultados encontrados nessa pesquisa de modo a desenvolver projetos que considerem produtos e serviços mais adequados para as mães e para as crianças. Desse modo, a partir da identificação dos concerns e das reações emocionais das mães quanto à vacinação de crianças de 0 a 4 anos, é possível apontar diretrizes projetuais para a caracterização de produtos e serviços para o processo de vacinação infantil, buscando potencializar os efeitos positivos e minimizar os efeitos negativos das reações emocionais identificadas, independente de serviços públicos ou particulares.

\section{DIRETRIZES PROJETUAIS PARA O SISTEMA DE VACINAÇÃO}

Em termos projetuais, como indicado por Tonetto e Costa (2011), percebe-se que o designer pode selecionar as emoções explicitadas no Quadro 2 para potencializá-las ou amenizá-las intencionalmente na concepção de projetos de produtos ou serviços. Além disso, destaca-se também, que outras dimensões da experiência, como experiências estéticas e de significado propostas por Desmet e Hekkert (2007), podem ser exploradas intencionalmente e priorizadas na concepção de projetos para amenizar ou potencializar essas emoções. Tonetto e Costa (2011) ressaltam ainda, que os designers podem apenas prever ou manipular o impacto emocional de seus projetos se estiverem conscientes das preocupações do público ao qual se destinam os produtos e serviços. Conhecer essas preocupações foi uma das 
intenções desse trabalho. Para determinar as diretrizes projetuais, objetiva-se apontar questões do que deve ser levado em consideração no momento de futura projetação.

Para minimizar a apreensão relativa à falta de clareza das informações passadas pelos profissionais responsáveis pela vacinação, potencializando ao mesmo tempo a segurança das mães, é imprescindível estabelecer um serviço que informe objetivamente, sem contradições em diferentes locais de vacinação. Sugere-se o projeto de criação de serviços informatizados que integrem o fluxo de informações disponibilizadas por médicos e enfermeiros, que contemple os locais de vacinação, documentos do médico, dos enfermeiros, da mãe e da criança, procedimentos sobre as vacinações, explicações sobre os benefícios de cada vacina e as reações adversas que podem provocar. A partir disso, aponta-se ainda a necessidade de automatização para o preenchimento da caderneta, para a identificação dos materiais e utensílios necessários para o atendimento e para sistemas de controle como avisos para a realização das próximas vacinas, profissionais envolvidos, históricos de saúde, comprovação dos insumos utilizados e autenticação do processo de vacinação da criança. Dessa forma, pode-se promover a transparência das informações, o controle do processo pelos pais e o resgate de informações quando a criança estiver na fase adulta. Com a estruturação e o processamento de dados digitais, pode-se possibilitar a conexão das informações com programas de saúde públicos. Reforça-se que, uma linguagem visual adequada para o projeto gráfico do sistema informatizado pode contribuir na comunicação das informações.

Esse tipo de sistema informatizado e integrado serve, para as mães, como uma alternativa mais eficiente à caderneta de saúde, que já proporcionava segurança, mas favorece principalmente os postos e clínicas de vacinação, pois padroniza as informações e propicia que as enfermeiras mantenham-se atualizadas e capazes de comunicar às mães com maior clareza. Para tanto, também se propõe a criação de serviços de orientação, capacitações para os profissionais envolvidos no atendimento da criança. Além disso, aponta-se ser necessário dar atenção à padronização dos procedimentos de vacinação pelos profissionais de enfermagem, evitando assim, riscos de erros. Os rótulos das vacinas podem ser ordenados por cores ou outra forma de diferenciação, de modo que a mãe saiba, visualmente, qual vacina está sendo aplicada.

Quanto à insegurança em relação à higiene e esterilização do ambiente, recomenda-se atenção na projetação de peças facilmente esterilizáveis e revestimentos descartáveis para as mesas de acomodação dos bebês e o reforço na eficácia de serviços de limpeza para eliminação de riscos de contaminação. Importante deter atenção no projeto de produtos descartáveis que não poluam o meio ambiente e que sejam fáceis de serem coprocessados, levando em consideração o impacto ambiental e os riscos gerados pelo descarte de resíduos perigosos de origem hospitalar. Propõe-se também, espaços adequados e exclusivos para vacinação, evitando a contaminação dos utensílios por outros procedimentos médicos.

Para a irritação, relacionada aos problemas de infraestrutura, propõe-se diretrizes para amenizar essa emoção, tal como a criação de ambientes amplos e acessíveis, sempre que possível, como por exemplo, espaços que facilitem a passagem de pais e filhos com carrinhos. Deve-se também, projetar a inserção de objetos atrativos para as crianças, a fim de distraí-los no momento da vacinação, como por exemplo, decoração da sala, brinquedos coloridos, uniforme e apresentação visual dos atendentes. Além disso, também se aponta a necessidade de diferenciação no acesso 
de entrada e saída dos pacientes no ambiente de vacinação, para que entre um atendimento e outro, não haja o contato com outras crianças, adultos ou doentes. É necessário ater-se a um tipo de atendimento personalizado, que priorize o relacionamento com as mães e as crianças ao longo de todo o serviço de vacinação.

Quanto à diminuição da angústia das mães, sugere-se atenção para o desenvolvimento de procedimentos menos dolorosos e menos invasivos, que diminuam a sensação de dor das crianças pela perfuração da pele. Mas também é importante ater-se às abordagens realizadas pelos profissionais, preparando os médicos e enfermeiros, mediante treinamentos lúdicos, para que prestem um serviço de atendimento diferenciado, que contribua com a tranquilidade da criança. Por fim, direciona-se para a criação de outros serviços que possam contribuir ainda mais para o bem-estar das mães, como a personalização no atendimento de mulheres ainda em gestação, a fim de adiantar o esclarecimento das informações e proporcionar maior conforto e tranquilidade.

\section{CONCLUSÃO}

Este artigo apresentou a análise e discussão sobre os resultados da pesquisa exploratória realizada a partir de entrevistas em profundidade com oito mães de crianças entre zero e quatro anos de idade em período de intensa vacinação. A pesquisa foi realizada com base na teoria dos appraisals, optando-se pelo modelo temático de avaliação. Foram investigados os efeitos emocionais, as causas dessas emoções e os concerns relacionados ao uso dos produtos e serviços disponibilizados para vacinação.

Deste modo, foram identificadas na análise de conteúdo das entrevistas, reações emocionais como apreensão, insegurança, irritação, angústia e segurança. Também se discutiu o fato de que garantir o bem-estar das mães torna-se relevante, pois as reações emocionais delas podem interferir nas reações das crianças. Destacouse ainda que as emoções dessas mães foram provocadas durante a prestação do serviço de vacinação tanto público, quanto privado.

Com a análise e a discussão dos resultados foi possível apontar diretrizes projetuais para que designers possam explorar a pesquisa e propor soluções efetivas e inovadoras que contribuam para a minimização das reações negativas e a potencialização das reações positivas no processo de vacinação infantil.

Por fim, compreendeu-se que futuras pesquisas podem ser realizadas com foco na avaliação componencial, objetivando a identificação de outras emoções. Também pode ser proposto um aprofundamento da pesquisa, mediante a análise das reações emocionais das crianças, além das emoções das mães.

\section{REFERÊNCIAS}

DESMET, P. M. A. Designing emotions. Delft: Universidade Tecnológica de Delft, 2002.

DESMET, P. M. A., \& HEKKERT, P. Framework of product experience. International Journal of Design, 1(1), 57-66, 2007.

DEMIR, E.; DESMET, P.; HEKKERT, P. Appraisal Patterns of Emotions in Human-Product Interaction. Internacional Journal of Design, Vol.3, No2, 41-51, 2009. 
HOLBROOK, M.B.; HIRSCHMAN, E.C. The experiential aspects of consumption: consumer fantasy, feelings and fun. Journal of Consumer Research, 9 (2): 132-140, 1982.

LAZARUS, S. Emotion and Adaptation. New York. Oxford University Press, 1991.

MERONI, A.; SANGIORGI, D. Design for Services. From Service Design to Designing for Services as a 'mean' for society transformation. Gower Publishing, 2011.

PARROT, G. W. Emotions in social psychology: essential readings. Psychology Press: Philadelphia, 2001.

PORTAL BRASIL. Vacinação. Disponível na internet por http em: <http://www.brasil.gov.br/sobre/saude/programas-e-campanhas/campanhas-devacinacao-2>. Acesso em: 01 dez. 2012.

PORTAL DA SAÚDE. Vacinação. Disponível na internet por http em: <http://portal.saude.gov.br/portal/saude/profissional/visualizar_texto.cfm?idtxt=3095 0\&janela=1>. Acesso em: $01 \mathrm{dez} .2012$.

SCHERER, K.; SCHORR, A.; JOHNSTONE, T. Appraisal processes in Emotion. New York, NY: Oxford University Press, 2001.

SCHERER, K. What are emotions? And how can they be measured? In: Social Science Information. v. 44, n. 4, 2005.

TONETTO, L.; COSTA, F. Design Emocional: conceitos, abordagens e perspectivas de pesquisa. Strategic Design Research Journal, volume 4, number 3, 132-140 SeptemberDecember, 2011.

VARELLA, Dr. Dráuzio. Vacinação Infantil. Disponível na internet por http em: <http://drauziovarella.com.br/doencas-e-sintomas/vacinacao-infantil/>. Acesso em: 02 dez. 2012. 